\title{
Cell death and ultrastructural alterations in Leishmania amazonensis caused by new compound 4-Nitrobenzaldehyde thiosemicarbazone derived from S-limonene
}

\author{
Elizandra Aparecida Britta', Débora Botura Scariot ${ }^{1}$, Hugo Falzirolli², Tânia Ueda-Nakamura', \\ Cleuza Conceição Silva ${ }^{2}$, Benedito Prado Dias Filho ${ }^{1}$, Redouane Borsali ${ }^{3}$ and Celso Vataru Nakamura ${ }^{1{ }^{*}}$
}

\begin{abstract}
Background: The treatment of leishmaniasis with pentavalent antimonials is problematic because of their toxicity. Investigations of potentially active molecules are important to discover less toxic drugs that are viable economic alternatives for the treatment of leishmaniasis. Thiosemicarbazones are a group of molecules that are known for their wide versatility and biological activity. In the present study, we examined the antileishmania activity, mechanism of action, and biochemical alterations produced by a novel molecule, 4-nitrobenzaldehyde thiosemicarbazone (BZTS), derived from S-limonene against Leishmania amazonensis.
\end{abstract}

Results: BZTS inhibited the growth of the promastigote and axenic amastigote forms, with an $I_{50}$ of 3.8 and $8.0 \mu \mathrm{M}$, respectively. Intracellular amastigotes were inhibited by the compound with an $\mathrm{IC}_{50}$ of $7.7 \mu \mathrm{M}$. BZTS also had a $\mathrm{CC}_{50}$ of $88.8 \mu \mathrm{M}$ for the macrophage strain J774A1. BZTS altered the shape, size, and ultrastructure of the parasites, including damage to mitochondria, reflected by extensive swelling and disorganization of the inner mitochondrial membrane, intense cytoplasmic vacuolization, and the presence of concentric membrane structures inside the organelle. Cytoplasmic lipid bodies, vesicles inside vacuoles in the flagellar pocket, and enlargement were also observed. BZTS did not induce alterations in the plasma membrane or increase annexin-V fluorescence intensity, indicating no phosphatidylserine exposure. However, it induced the production of mitochondrial superoxide anion radicals.

Conclusions: The present results indicate that BZTS induced dramatic effects on the ultrastructure of L. amazonensis, which might be associated with mitochondrial dysfunction and oxidative damage, leading to parasite death.

Keywords: Antileishmanial activity, Benzaldehyde thiosemicarbazone, Leishmania amazonensis, Ultrastructural alterations, Mitochondria damage, Electron microscopy, Cellular disorganization

\section{Background}

Leishmaniasis represents a serious public health problem in 88 countries, occurring mainly in economically disadvantaged regions [1]. Few drug therapy discoveries have been made in recent decades. The first-line treatment for cutaneous leishmaniasis consists of only pentavalent antimonials, but their toxicity is a major issue [2]. Although

\footnotetext{
* Correspondence: cvnakamura@uem.br

'Programa de Pós-graduação em Ciências Farmacêuticas, Universidade Estadual de Maringá, Avenida Colombo, Jd. Universitário, Maringá, PR 5790, Brazil

Full list of author information is available at the end of the article
}

these drugs are not an ideal treatment, none of the other many investigated drugs are better than pentavalent antimonials with regard to safety, efficacy, and cost [3,4]. Investigations of potentially active molecules are important to discover less toxic drugs that are viable economic alternatives for the treatment of leishmaniasis.

Thiosemicarbazones are a group of molecules whose biological properties have long been investigated [5]. Antiviral, antiprotozoal, antitumor, antimicrobial, and antifungal properties have been reported for some thiosemicarbazones [6,7]. Phase 2 clinical trials that investigated 
3-aminopyridine-2-carboxaldehyde thiosemicarbazone, also known as Triapine, were completed for the treatment of metastatic renal cell carcinoma, and patients are currently being recruited for Phase 2 clinical trials for vaginal cancer $[8,9]$.

Thus, this chemical group is known for its wide versatility and biological activity, which is mainly associated with a metal complex or the presence of different substituent groups, such as limonene. These purposeful molecular changes appear to improve the biological properties of the molecule, increase the potential for activity, and lessen cytotoxicity in an attempt to reach a specific target in the parasite, such as mitochondria [10-12]. The main cellular targets of some thiosemicarbazones have been previously reported, indicating from molecular and chemistry targets, such as viral RNA synthesis and tyrosinase activity respectively, to organelles dysfunction, like mitochondria function [13-15]. The present study examined the antileishmania activity and mechanism of action of a novel molecule, 4-nitroben zaldehyde thiosemicarbazone, derived from $S$-limonene against L. amazonensis.

\section{Results}

\section{BZTS inhibited L. amazonensis proliferation in vitro}

To determine the effects of BZTS (Figure 1) on the cellular proliferation of L. amazonensis, the parasites were incubated with BZTS $(2.7,13.9,27.7,139$ and $277 \mu \mathrm{M})$ for $72 \mathrm{~h}$. BZTS dose-dependently inhibited the growth of the promastigote and axenic amastigote forms, with an $\mathrm{IC}_{50}$ of $3.8 \mu \mathrm{M}$ and $8.0 \mu \mathrm{M}$, respectively. BZTS exerted activity against intracellular amastigotes at an $\mathrm{IC}_{50}$ value of 7.7 $\mu \mathrm{M}$. BZTS was also evaluated for its cytotoxic effects on the macrophage strain J774A1, with a $\mathrm{CC}_{50}$ of $88.8 \mu \mathrm{M}$. Cytotoxicity in J774A1 macrophages and activity against promastigotes, axenic amastigotes, and intracellular amastigotes were compared using the selectivity index (SI; ratio: $\mathrm{CC}_{50}$ J774A1 macrophage/ $\mathrm{IC}_{50}$ protozoa). The observed SIs were 23.4, 11.1, and 11.5 for the promastigotes, axenic amastigotes, and intracellular amastigotes, respectively. These results demonstrate that BZTS is more toxic to the protozoa than to macrophages (Additional files 1,2 , and 3 ).

\section{BZTS induced morphological and ultrastructural changes}

Scanning electron microscopy revealed that BZTS caused morphological alterations in the promastigote forms of $L$. amazonensis compared with untreated parasites, which showed typical characteristics, with an elongated shape and free flagellum. Figure 2 shows alterations in shape and size and cellular disintegration in BZTS-treated parasites. These alterations were more pronounced in parasites treated with the $\mathrm{IC}_{90}(13.9 \mu \mathrm{M})$ of BZTS. To evaluate the alterations in cell shape and size in promastigote forms

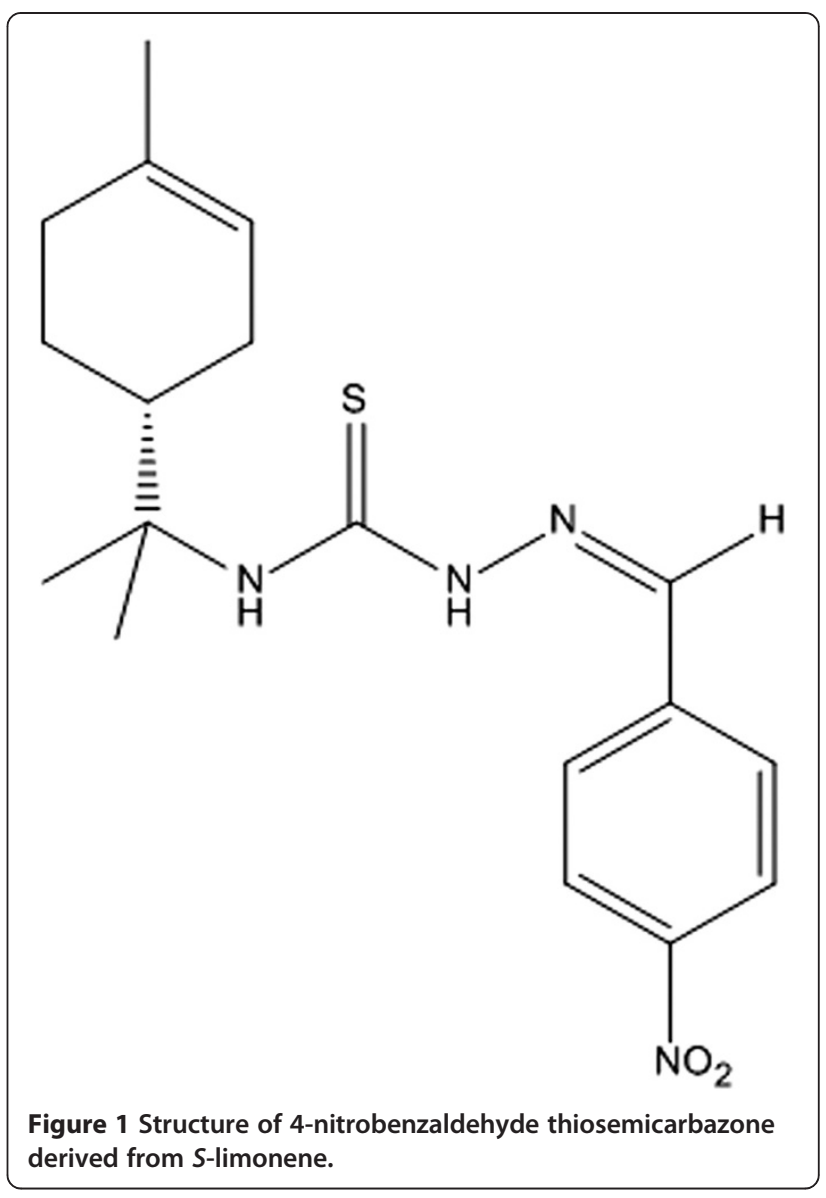

revealed by SEM, the treated parasites were assessed by flow cytometry. The histogram showed that BZTStreated parasites exhibited a reduction of parasite volume (Figure 3). A dose-dependent decrease in cell volume was observed $(32.3 \%, 83.8 \%, 86.3 \%$, and $89.3 \%$ at BZTS concentrations of $55,139,277$, and $555 \mu \mathrm{M}$, respectively).

Transmission electron microscopy of BZTS-treated promastigotes and axenic amastigotes showed the presence of several ultrastructural alterations (Figures 4 and 5). BZTS induced severe damage in parasite mitochondria, reflected by extensive swelling and disorganization in the inner mitochondrial membrane, intense cytoplasmic vacuolization, and the presence of concentric membrane structures inside the organelle. Cytoplasmic lipid bodies, vesicles inside vacuoles in the flagellar pocket, and enlargement were also observed.

To confirm the accumulation of lipid bodies in treated promastigotes observed by TEM, we evaluated the existence of this structure using Nile Red staining, which stains neutral lipids. Fluorescence microscopy revealed the presence of lipid bodies in control promastigotes, but the presence of lipid bodies was enhanced after treatment with the $\mathrm{IC}_{50}$ and $\mathrm{IC}_{90}$ of BZTS for $72 \mathrm{~h}$ (Figure 6). This structure 

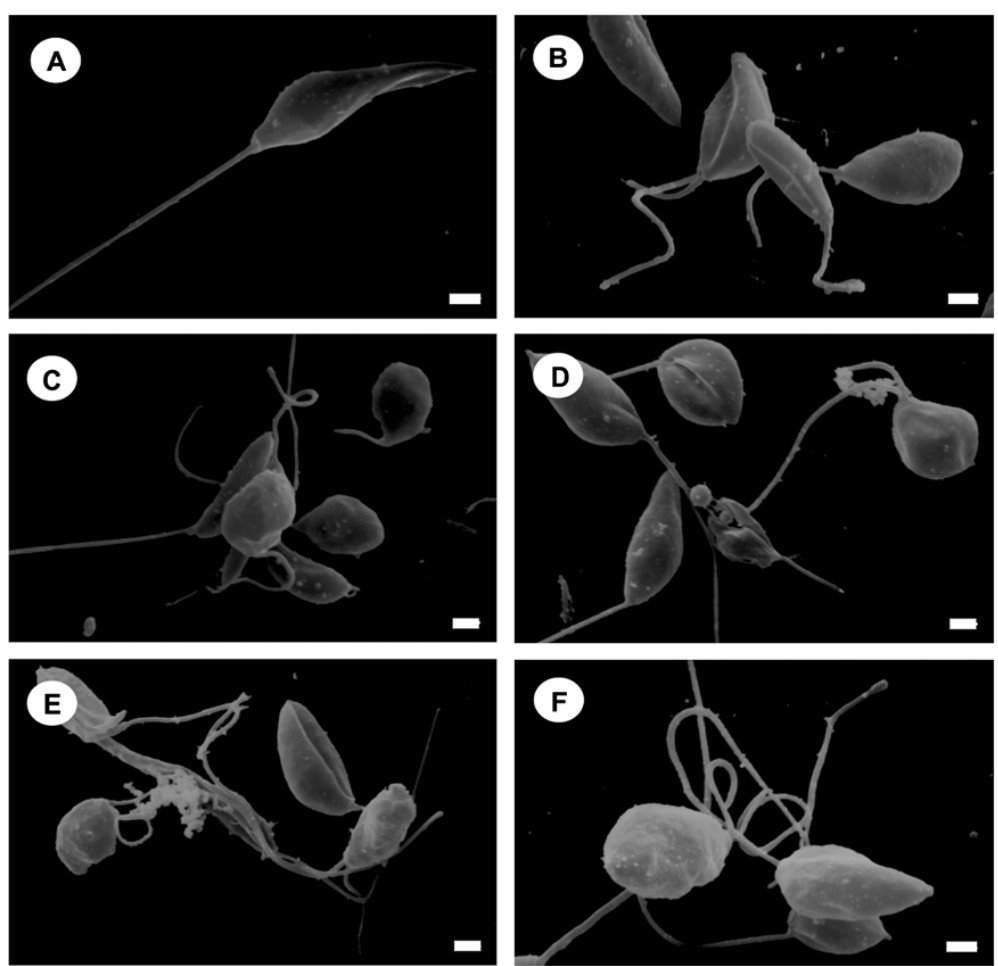

Figure 2 Scanning electron microscopy of Leishmania amazonensis promastigotes. The figure shows control promastigotes (A) and promastigotes treated with concentrations that corresponded to the $I_{50}(\mathbf{B}-\mathbf{D})$ and $I C_{90}(\mathbf{E}, \mathbf{F})$ of $B Z T S$. (A) The protozoan presented typical characteristics, with an elongated shape and free flagellum. (B-F) BZTS induced alterations in the shape and size of the protozoan. Scale bar $=1 \mu \mathrm{m}$.

appeared to be randomly distributed throughout the parasite cytoplasm.

\section{BZTS altered $\Delta \Psi \mathrm{m}$ but not cell membrane integrity}

Alterations in cell membrane integrity were evaluated by PI staining, which is a nucleic acid stain that penetrates cells with a compromised plasma membrane and does not cross the membranes of live cells. BZTStreated, PI-labeled promastigotes did not show significant permeabilization of the plasma membrane compared with untreated parasites. BZTS at concentrations of $55,139,277$, and $555 \mu \mathrm{M}$ showed PI fluorescence intensity of $5.3 \%, 7.7 \%, 11.3 \%$, and $12.7 \%$, respectively. The negative control showed PI fluorescence intensity of $4.2 \%$, and the positive control (digitonine) showed PI fluorescence intensity of $47.3 \%$ (Figure 7).

Transmission electron microscopy demonstrated that BZTS induced alterations in parasite mitochondria, and we evaluated the $\Delta \Psi \mathrm{m}$ by flow cytometry using Rh 123 , which accumulates within energized mitochondria. The histograms (Figure 8) revealed a decrease in total Rh 123 fluorescence intensity, indicating mitochondrial membrane depolarization. BZTS at concentrations of 55, 139, 277 , and $555 \mu \mathrm{M}$ caused $46.2 \%, 77.3 \%, 78.5 \%$, and $72.4 \%$ decreases in total Rh 123 fluorescence intensity, respectively, compared with the negative control. Such decreases were further quantified as IV values. Promastigotes that were treated with 55, 139, 277, and $555 \mu \mathrm{M}$ BZTS had IV values of $-0.46,-0.77,-0.78$, and -0.72 , respectively.

\section{BZTS did not induce phosphatidylserine exposure}

Phosphatidylserine (PS) is a phospholipid that is confined to the inner face of the plasma membrane and translocates to the cell surface in apoptotic cells. Annexin V is a calcium-dependent, phospholipid-binding protein that preferentially binds PS $(1,26,29)$. Annexin V-FITC was used to evaluate the externalization of phosphatidylserine. As shown in Figure 9, no significant increase in annexin-V fluorescence intensity was observed compared with untreated parasites, indicating no phosphatidylserine exposure. The histograms showed annexin-V fluorescence intensity of $12.4 \%, 11.9 \%, 13.9 \%$ and $14.2 \%$ at BZTS concentrations of $55,139,277$, and $555 \mu \mathrm{M}$, respectively. The negative control showed annexin-V fluorescence intensity of $8.6 \%$. The positive control (CCCP) showed a $71.6 \%$ increase in annexin- $\mathrm{V}$ fluorescence intensity.

\section{BZTS caused mitochondrial $\mathrm{O}_{2}^{-}$production}

After observing severe damage in parasite mitochondria and mitochondrial membrane depolarization, we evaluated the production of $\mathrm{O}_{2}^{-}$. Mitochondrion-derived $\mathrm{O}_{2}^{-}$ production was evaluated using MitoSOX reagent, which 

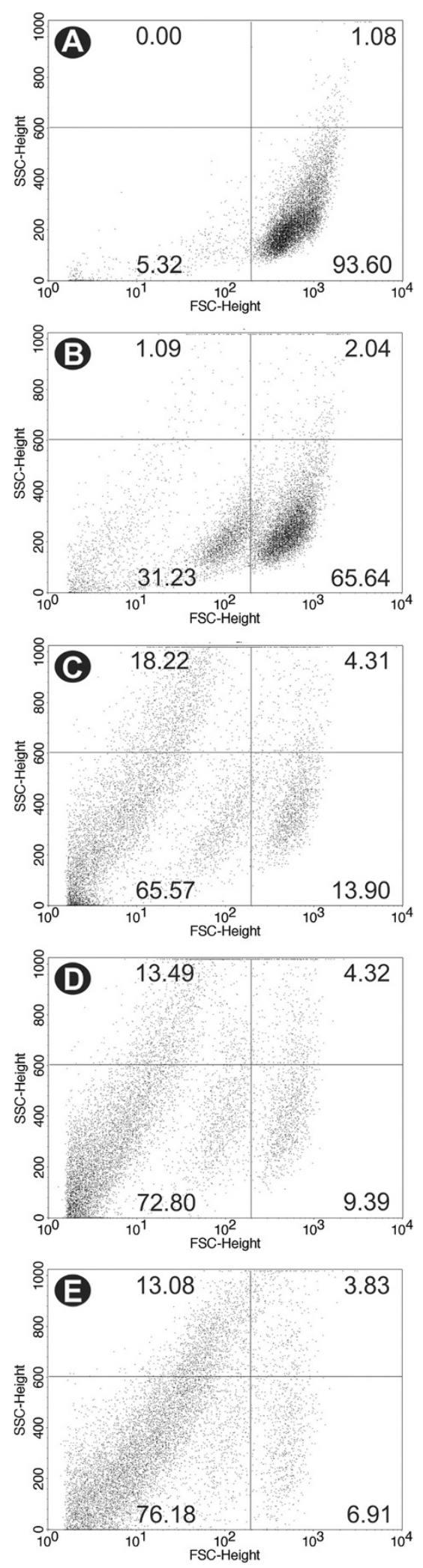

Figure 3 Cell volume analysis by flow cytometry of untreated Leishmania amazonensis promastigotes $(A)$ and promastigotes treated with $55,139,277$, and $555 \mu \mathrm{M}$ BZTS, respectively (B-E), after $24 \mathrm{~h}$ of incubation at $25^{\circ} \mathrm{C}$. SSC-H, side scatter; FSC-H, forward scatter.

measures the mitochondrial accumulation of superoxide based on its hydrophobic nature and positively charged triphenylphosphonium moiety. MitoSOX oxidation was higher in BZTS-treated parasites compared with controls. The increase in MitoSOX oxidation in BZTS-treated promastigotes was observed after $1 \mathrm{~h}$ of incubation. Treatment with 277 and $555 \mu \mathrm{M}$ caused higher MitoSOX oxidation than the lower concentrations (Figure 10).

\section{Discussion}

Drug therapy for leishmaniasis has not significantly changed since the beginning of the 20th century, and adequate treatment remains a problem because of toxicity and side effects. New treatments that are more effective and less toxic are urgently needed [16]. Investigations of new drugs with antileishmanial activity, including both natural products and synthetic compounds, have been performed worldwide [17-21].

In the present study, we showed that BZTS had antiproliferative effects on promastigotes and axenic amastigotes, with a reduction of survival of intracellular parasites in macrophages. Moreover, BZTS was more selective for the protozoa than for mammalian cells. BZTS exerted its antileishmanial activity by affecting parasite mitochondrial function, indicated by TEM, variations in $\Delta \Psi \mathrm{m}$ by flow cytometry using $\mathrm{Rh} 123$, and the production of $\mathrm{O}_{2}^{-}$evaluated by MitoSOX oxidation.

The single mitochondrion of the kinetoplastid parasite is an attractive chemotherapeutic target because its functional features are markedly distinct from mammalian mitochondria [22]. Our previous studies showed the in vitro antileishmanial activity of benzaldehyde thiosemicarbazone derived from limonene complexed with copper against $L$. amazonensis, with an effect on mitochondrial function [13]. Inácio et al. (2012) reported that epigallocatechin-3-gallate induced death in L. amazonensis by directly affecting mitochondrial physiology in treated parasites. These effects were detected as ultrastructural alterations of the mitochondria, organelle injury, and a decrease in Rh 123 fluorescence. Monzote et al. (2014) [23] suggested that the antileishmania activity of the essential oil and major constituents (i.e., ascaridole, carvacol, and caryophllene oxide) of Chenopodium ambroisiodes against L. amazonensis promastigotes is correlated with mitochondrial dysfunction, reflected by $\Delta \Psi \mathrm{m}$. Further studies by our group demonstrated ultrastructural mitochondrial alterations and $\Delta \Psi \mathrm{m}$ changes in parasites treated with thiophene derivatives isolated from the aerial parts of 

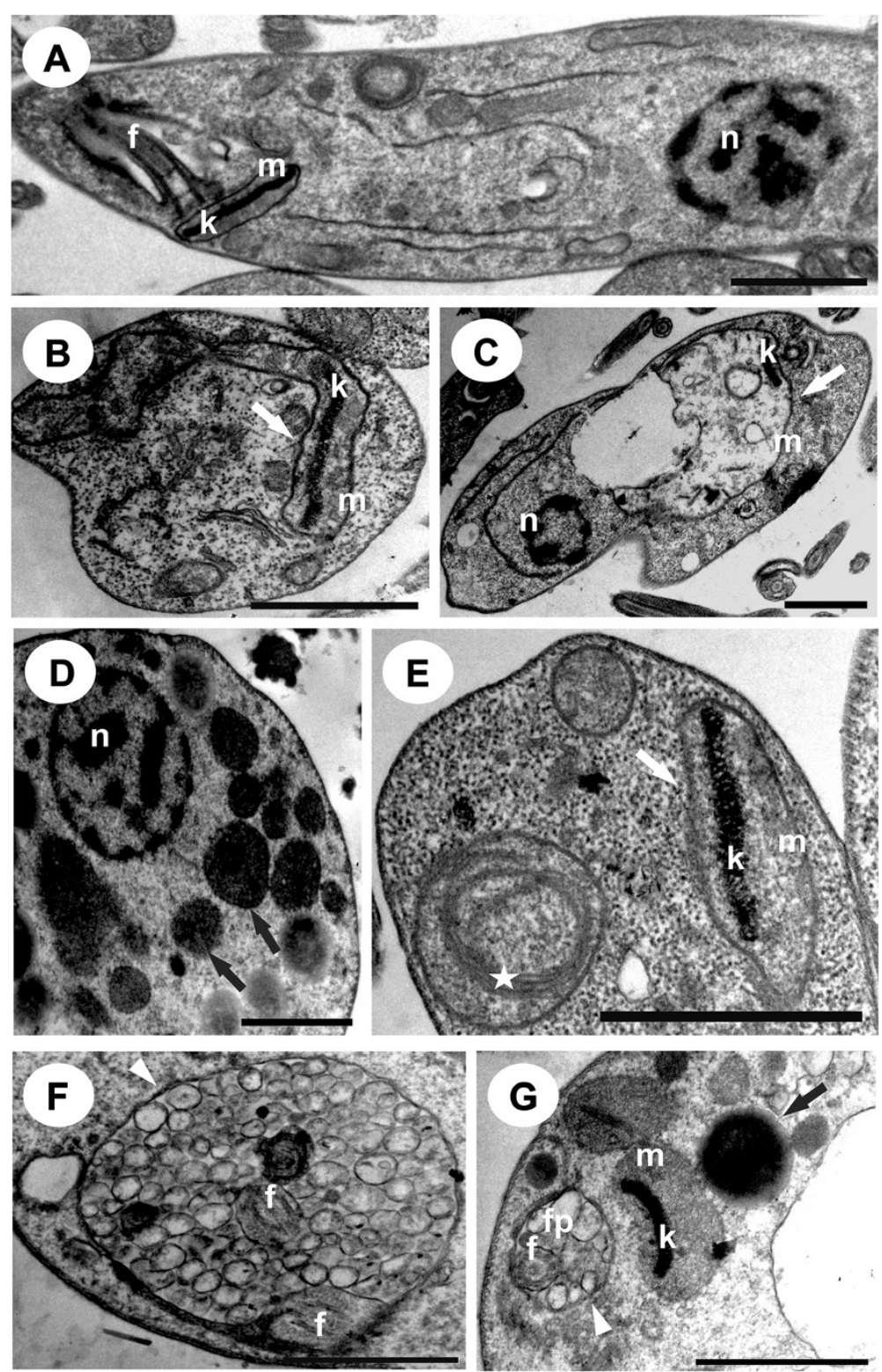

Figure 4 Ultrathin sections of Leishmania amazonensis promastigotes without treatment that presented a normal ultrastructure (A) and promastigotes treated with BZTS at concentrations that corresponded to the $I C_{50}(B-D)$ and $I C_{90}(E, G)$. White arrows indicate swollen mitochondria. Black arrows represent lipid-storage bodies. White arrowheads indicate the presence of vesicles inside the flagellar pocket. The star indicates the presence of concentric membranous structures. $n$, nucleus; $\mathrm{m}$, mitochondrion; k, kinetoplast; f, flagellum; fp, flagellar pocket. Scale bar $=1 \mu \mathrm{m}$.

Porophyllum ruderale, a $\beta$-carbolinic compound ( $N$-butyl1-[4-dimethylamino]phenyl-1,2,3,4-tetrahydro- $\beta$-carboline-3-carboxamide), and eupomatenoid-5, a neolignan isolated from the leaves of Piper regnellii [24-27]. LuqueOrtega et al. (2010) [28] also showed that benzophenonederived bisphosphonium salts present antileishmania activity against promastigotes of the Leishmania donovani causing a dramatically swollen mitochondrion in treated parasites, and a decrease of the electrochemical mitochondrial potential.
Mitochondrial changes may be a consequence of many harmful effects induced by endogenous toxic compounds, such as reactive oxygen species (ROS). BZTS induced the production of these compounds, which may be responsible for mitochondrial injury and the induction of oxidative damage in lipids and proteins, reflected by variations in $\Delta \Psi \mathrm{m}$ using $\mathrm{Rh} 123$ and the production of $\mathrm{O}_{2}^{-}$. These results are similar to those reported by Volpato et al. (2013) and Desoti et al. (2012) [29], in which Trypanosoma cruzi were treated with $N$-butyl- 

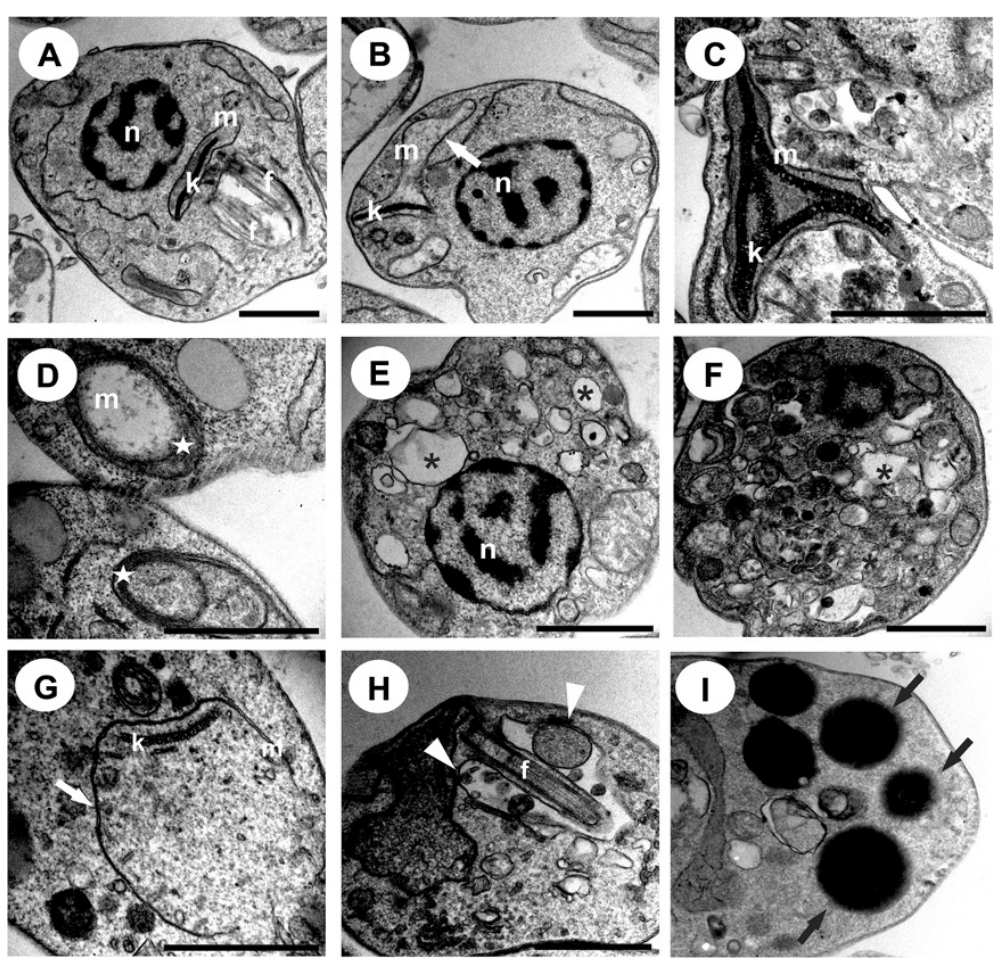

Figure 5 Ultrathin sections of Leishmania amazonensis axenic amastigotes without treatment that presented a normal ultrastructure (A) and treated with BZTS with concentrations that corresponded to the $I_{50}(B-F)$ and $I C_{90}(G, I)$. White arrows indicate swollen mitochondria. Black arrows represent lipid-storage bodies. White arrowheads indicate the presence of vesicles inside the flagellar pocket. The star indicates the presence of concentric membranous structures in the mitochondria. The asterisk indicates autophagic vacuoles. $n$, nucleus; $m$, mitochondrion; $k$, kinetoplast; f, flagellum; fp, flagellar pocket. Scale bar $=1 \mu \mathrm{m}$.
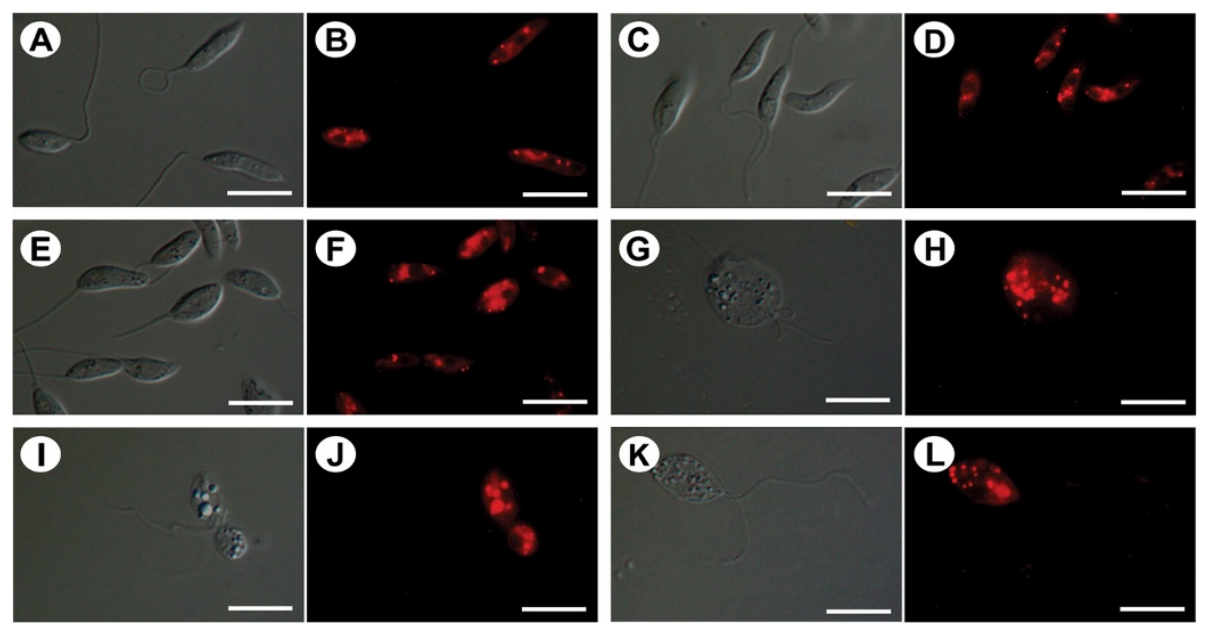

Figure 6 Differential interference contrast microscopy (DIC) and fluorescence microscopy with Nile Red staining of Leishmania amazonensis promastigotes without treatment $(\mathrm{A}, \mathrm{B})$ and treated with concentrations that corresponded to the IC $\mathrm{C}_{50}(\mathrm{C}-\mathrm{F})$ and IC 90 (G-L) of BZTS for $\mathbf{4 8} \mathbf{~ h}$. In the treated promastigotes, the images suggest the concentration-dependent accumulation of lipid-storage bodies in the cytoplasm. $(\mathbf{G}, \mathbf{I}, \mathbf{K})$ The parasites that were treated with the $\mathrm{IC}_{90}$ of BZTS were completely modified. Scale bar $=10 \mu \mathrm{m}$. 


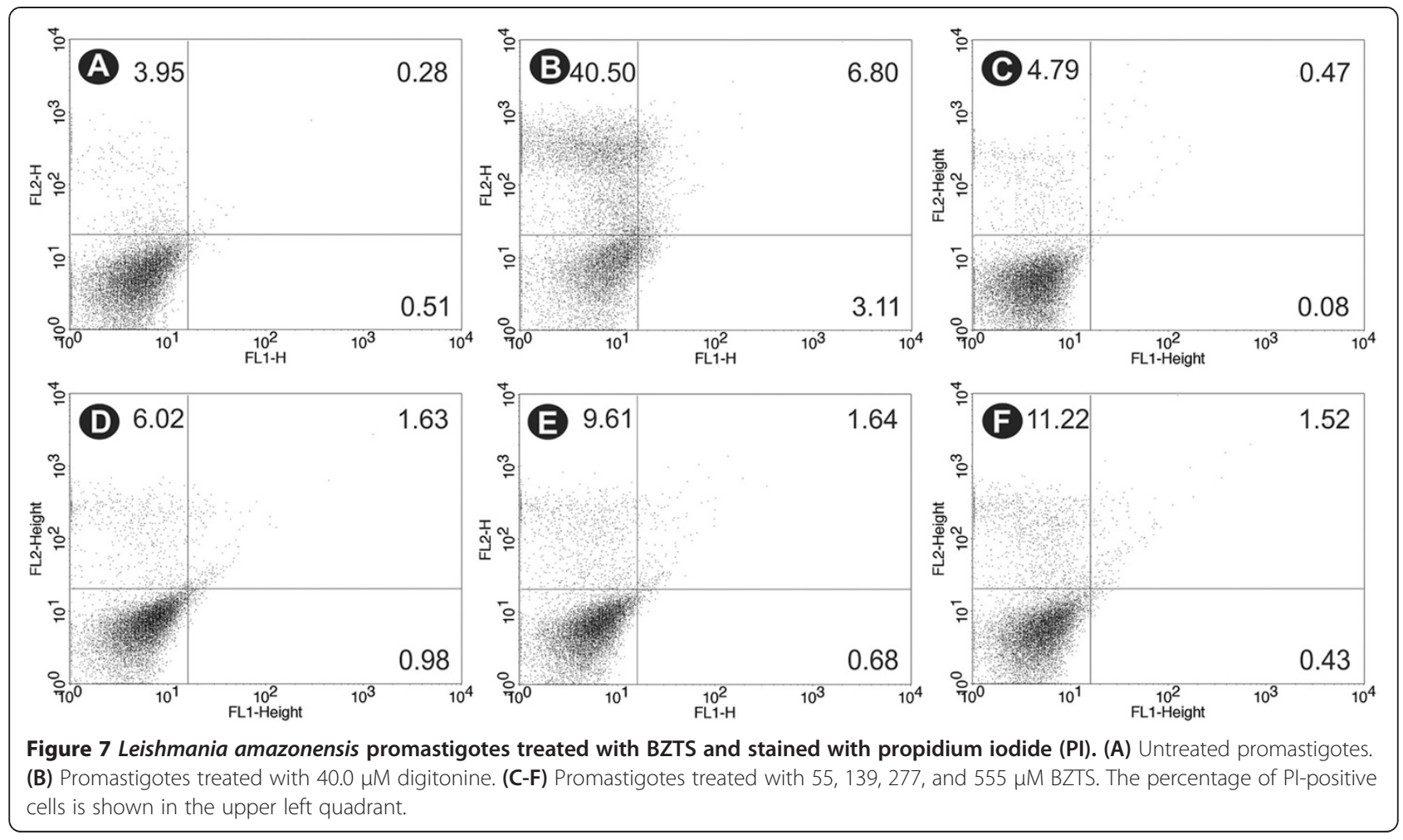

1-(4-dimethylamino) phenyl-1,2,3,4-tetrahydro- $\beta$-carboline-3-carboxamide and (-)-elatol extracted from the red macroalgae Laurencia dendroidea, respectively. This effect was also reported by Medina et al. (2012), in which $L$. amazonensis promastigotes were treated with tomatidine.

Electrons move through the mitochondrial respiratory chain during oxidative phosphorylation, and a proton

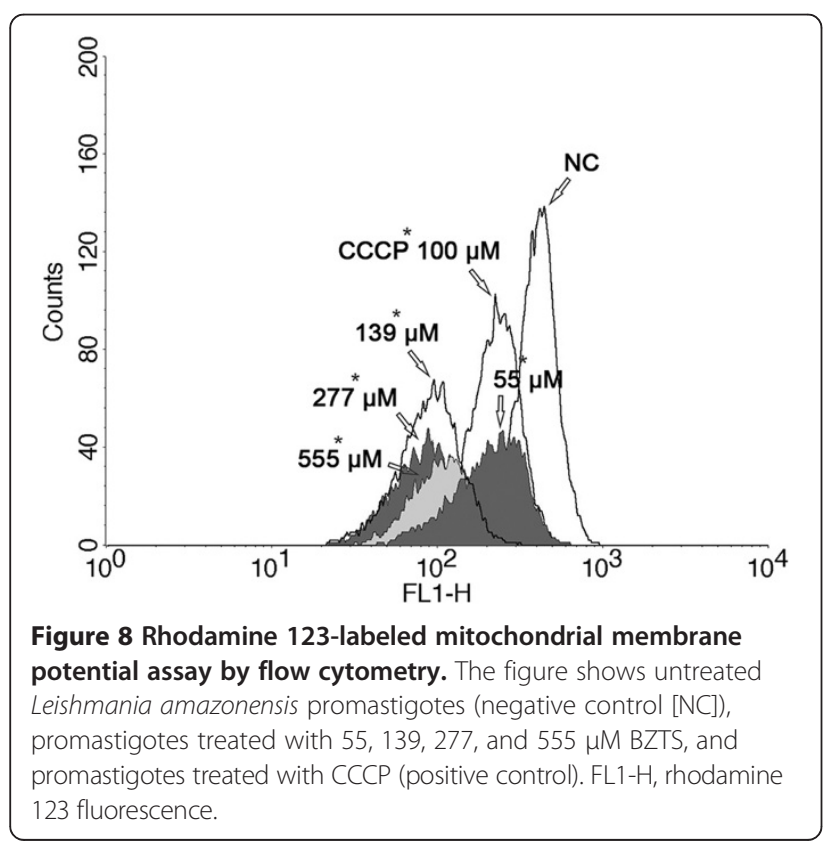

gradient is established across the inner mitochondrial membrane as an energy source for adenosine triphosphate (ATP). A decrease in Rh 123 fluorescence intensity suggests an increase in proton permeability across the inner mitochondrial membrane, which can decrease ATP synthesis and result in parasite death $[22,30]$. In the present study, we can infer that this process occurred, based on the Rh 123 assays. Furthermore, an association was observed between multivesicular bodies and mitochondrion profiles, likely indicating an autophagic process that removes damaged organelles. In the present study, TEM indicated the presence of several vesicles.

Mitochondrial ultrastructural alterations, the reduction of $\triangle \Psi \mathrm{m}$, and the increase in ROS production caused by BZTS may be explained by calcium release from mitochondria, indicating a direct action of BZTS on the organelle and the inhibition of sterol biosynthesis, leading to alterations in the lipid composition of mitochondrial membranes that can modify mitochondrial function [31,32]. Recently, Shioji Tiuman et al. (2014) [33] demonstrated that when the amastigotes were treated with parthenolide, a lipophilic hydrocarbon compound formed by units of isoprene, revealed mitochondrial damage, suggesting that this compound interferes with the mitochondrial membrane potential leading to alteration of ATP generation and in consequence cell damage takes place.

Another important effect of BZTS on parasites was the accumulation of intracellular lipid bodies in the cytoplasm indicated by fluorescence microscopy. The analysis 

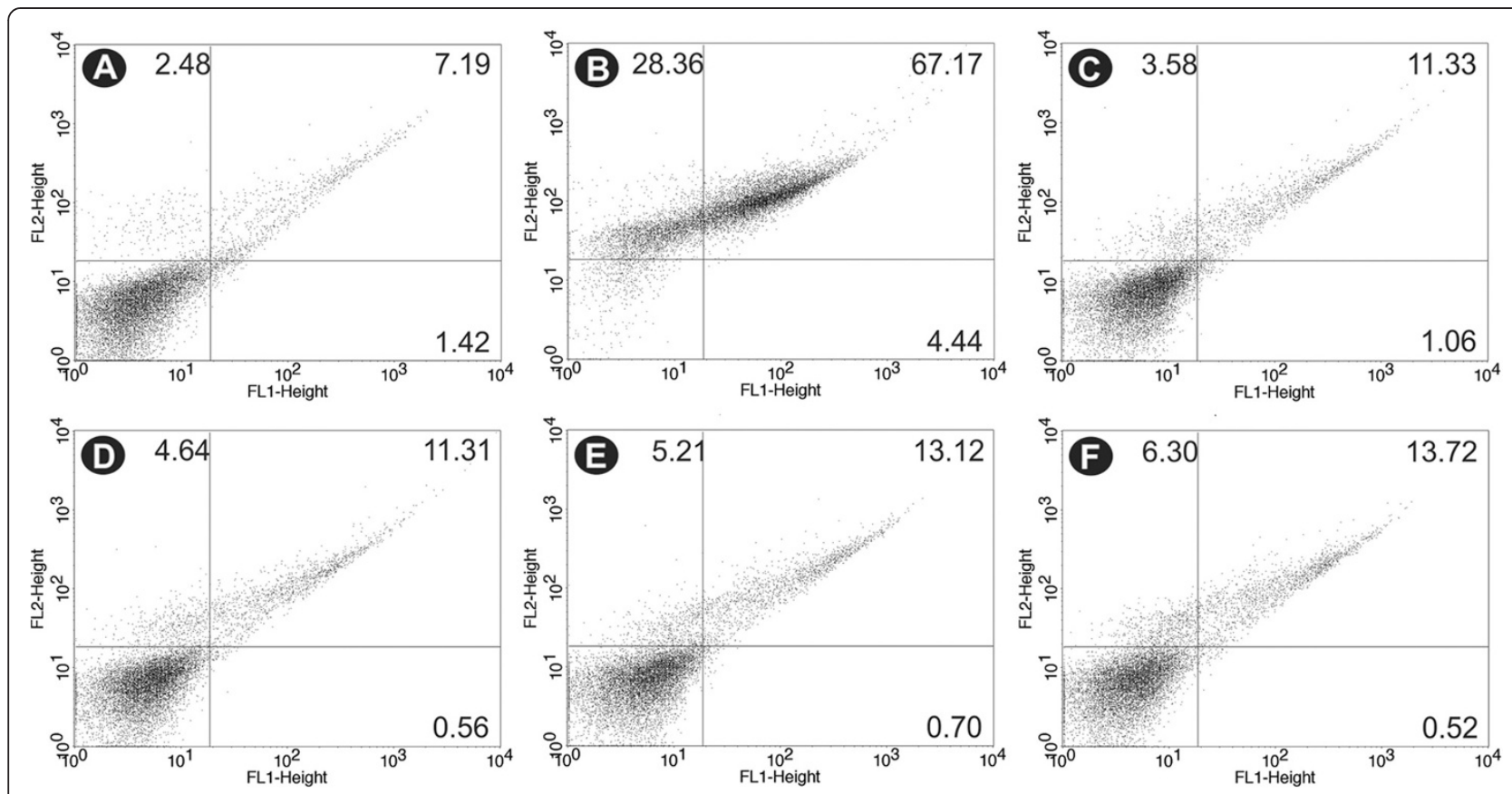

Figure 9 Phosphatidylserine exposure in untreated Leishmania amazonensis promastigotes (A), promastigotes treated with $100.0 \mu \mathrm{M}$ CCCP as the positive control (B), and promastigotes treated with $55 \mu \mathrm{M}$ (C), $139 \mu \mathrm{M}$ (D), $277 \mu \mathrm{M}$ (E), and $555 \mu \mathrm{M}$ (F) BZTS for $24 \mathrm{~h}$ using annexin-V FITC and PI.

of the treated parasites using differential interference contrast microscopy revealed alterations in shape, principally by treatment with the $\mathrm{IC}_{90}$ of BZTS, showing a rounded shape and evidence of the loss of cytoplasmic content. Similar results were reported by Macedo-Silva et al. (2011), in which promastigote forms were treated with amiodarone, an antiarrhythmic drug used for the treatment of Chagas' disease. The presence of intracellular lipid bodies may indicate alterations in phospholipids and sterol content $[30,34]$.

BZTS did not significantly increase annexin-V fluorescence intensity in treated parasites, indicating no

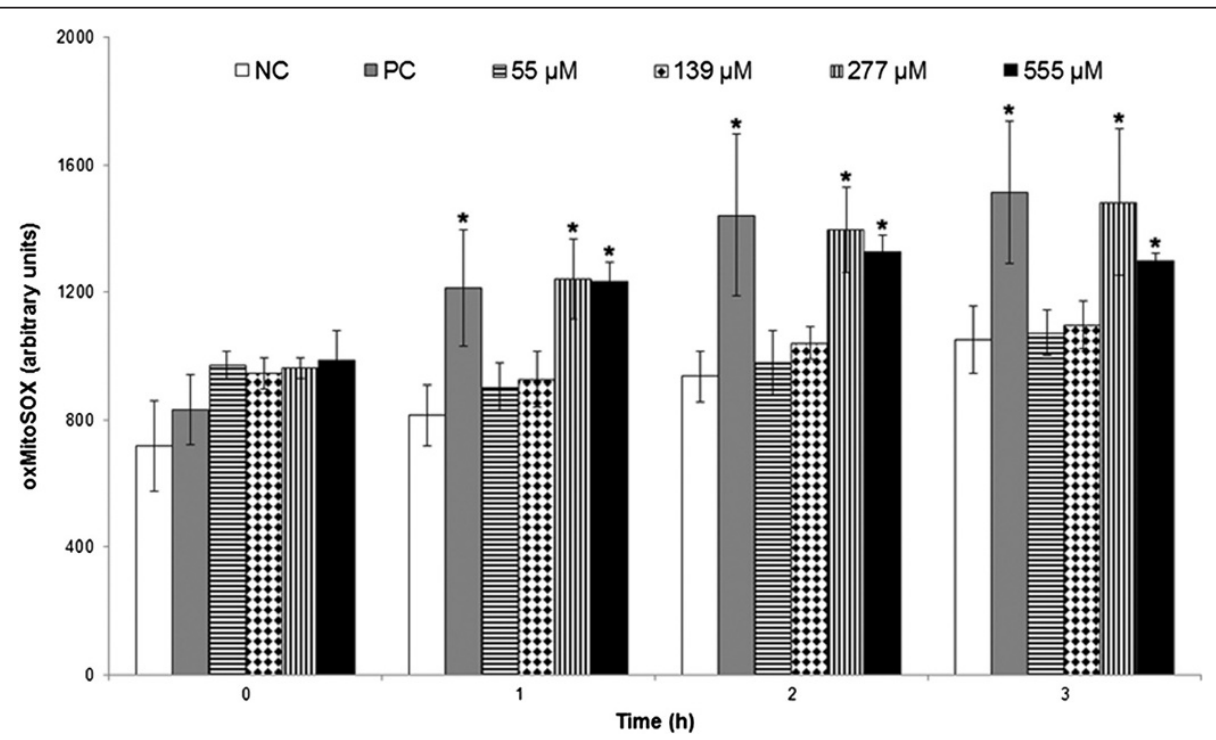

Figure 10 Mitochondrial $\mathrm{O}_{2}^{-}$production in Leishamania amazonensis promastigotes treated with 55, 139, 277, and $555 \mu \mathrm{M}$ BZTS for up to $\mathbf{3} \mathbf{~ h}$ using the fluorescence probe MitoSOX. Antimycin A $(10 \mu \mathrm{M})$ was used as a positive control. Fluorescence was measured with a VICTOR X3 spectrofluorometer (Perkin-Elmer). The results are expressed as the mean \pm standard error of MitoSOX oxidation (arbitrary units) from three independent experiments. ${ }^{*} p \leq 0.05$, significant difference from negative control group. 
phosphatidylserine exposure. In contrast, we found that BZTS induced several alterations in the mitochondrial ultrastructure and shape of the parasite. The mitochondria exhibited intense swelling, with the loss of matrix content, the presence of concentric membranes, inner membrane disorganization, severe changes in the mitochondrial membrane potential, the reduction of cell volume, and ROS production. These observations may indicate parasite death caused by apoptosis. Shivahare et al. (2014) [35] showed that a chromenochalcone exhibited leishmanicidal effects against Leishmania donovani by causing loss in membrane potential and phosphatidylserine exposure, thus exerting cell death via apoptosis in treated promastigotes.

However, the hypothesis of an autophagic process cannot be discarded because the presence of autophagic vacuoles, increases in the number of lipidic inclusions, and presence of concentric membranes in the cytoplasm are characteristic of autophagic processes and may be associated with the accumulation of aberrant lipids that are probably not entirely incorporated into the plasma membrane or the membranes that line the various cellular organelles [36].

\section{Conclusion}

Our results demonstrated that BZTS has potent antiproliferative activity against different evolutive forms of Leishmania amazonensis and induced marked effects on the morphology and ultrastructure of this parasite, such as interference with various cellular processes that led to changes in shape and mitochondrial function, the accumulation of lipid droplets, and features found in cells that die from apoptotic or autophagic processes.

\section{Methods}

\section{Chemistry}

All of the melting points were determined using a Microquímica model MQAPF-301 apparatus. Infrared spectra were obtained using $\mathrm{KBr}$ pellets in an FT-IR BOMEM spectrophotometer. Nuclear magnetic resonance $\left({ }^{1} \mathrm{H}\right.$ NMR and ${ }^{13} \mathrm{C}$ NMR $)$ spectra were obtained using a Varian Mercury Spectrometer $\left(300 \mathrm{MHz}\right.$ for ${ }^{1} \mathrm{H}$ and $75.5 \mathrm{MHz}$ for ${ }^{13} \mathrm{C}$ ) in $\mathrm{CDCl}_{3} / \mathrm{TMS}$ solution at $298^{\circ} \mathrm{C}$, with chemical shifts $(\delta)$ given in parts per million. Optical rotation was determined using a Perkin Elmer Model 343 polarimeter at $20^{\circ} \mathrm{C}$ and $589 \mathrm{~nm}$, with chloroform as the solvent.

\section{Synthesis of 4-nitrobenzaldehyde thiosemicarbazone derived from $\mathrm{S}$-limonene}

For the synthesis of 4-nitrobenzaldehyde thiosemicarbazone, a drop of solution of 5\% sulfuric acid and $1.0 \mathrm{mmol}(227.4 \mathrm{mg})$ thiosemicarbazide derived from $S$ limonene were added to a flask that contained $1.0 \mathrm{mmol}$
(151.2 mg) 4-nitrobenzaldehyde solubilized in ethanol (30 ml) (Yamaguchi et al., 2009) [37]. The mixture was stirred at room temperature for $30 \mathrm{~min}$, and the progression of the reaction was monitored by TLC. The solvent was evaporated under reduced pressure, and the crude product was recrystallized from a mixture of ethanol:chloroform (1:3) to yield yellow crystals: yield (93\%); melting point $\left(165.4^{\circ} \mathrm{C}\right)$; optical rotation $\left(\alpha_{\mathrm{D}}^{20}\right):-30.0^{\circ}[\mathrm{IV}$ $\left(\mathrm{KBr}, \mathrm{U}_{\max }\right)$ : $3325(\mathrm{NH}) ; 3291(\mathrm{NH}) ; 2990-2900(\mathrm{CH})$; $1544(\mathrm{C}=\mathrm{S}) ; 1373(\mathrm{C}=\mathrm{N}) .{ }^{1} \mathrm{H}$ NMR (300 MHz, $\left.\mathrm{CDCl}_{3}\right)$ : $\delta=1.57$ (s, 3H, H8'); 1.60 (s, 3H, H9'); 1.67 (s, 3H, H10'); 1.86 (m, 2H, H6'); 2.04 (m, 2H, H2'); 2.07 (m, 2H, H5'); 2.69 (m, 1H, H1'); 5.40 (m, 1H, H3'); 7.56 (sl, 1H, H4); 7.75 (dd, $J=8.7 ; 4.2 \mathrm{~Hz}, 2 \mathrm{H}, \mathrm{H3}$ "/H7"); 7.92 (s, 1H, H1"); 8.27 (dd, $J=8.7 ; 4.0 \mathrm{~Hz}, 2 \mathrm{H}, \mathrm{H} 4 " / \mathrm{H} 6$ "); 9.83 (sl, 1H, H2); ${ }^{13} \mathrm{C}$ NMR (75.5 MHz, $\left.\mathrm{CDCl}_{3}\right)$ : $\delta=23.3\left(\mathrm{C} 10^{\prime}\right) ; 23.9\left(\mathrm{C}^{\prime}\right) ; 24.1\left(\mathrm{C}^{\prime}\right)$; 24.2 (C6'); 26.5 (C2'); 31.0 (C5'); 40.8 (C1'); 59.1 (C7’); 120.2 (C3'); 124.1 (C4"/C6"); 127.5 (C3"/C7”); 134.1 (C4'); 138.5 (C1"); 139.7 (C2"); 148.2 (C5"); 175.1 (C3)] (Figure 1).

\section{Parasite culture}

Leishmania amazonensis promastigotes (MHOM/BR/ Josefa) were maintained at $25^{\circ} \mathrm{C}$ in Warren's medium [brain-heart infusion plus hemin $(10 \mu \mathrm{g} / \mathrm{mL})$ and folic acid $(10 \mu \mathrm{g} / \mathrm{mL}), \mathrm{pH} 7.2]$ supplemented with $10 \%$ heatinactivated fetal bovine serum (FBS; Gibco Invitrogen, New York, NY, USA). Axenic amastigotes were obtained by in vitro transformation of infective promastigotes by a progressive temperature increase and $\mathrm{pH}$ decrease. These forms were maintained in Schneider's medium (Sigma, St. Louis, MO, USA), pH 4.6, that contained 20\% FBS at $32^{\circ} \mathrm{C}$.

\section{In vitro antiproliferative assay}

Promastigotes in the logarithmic phase $\left(1 \times 10^{6}\right.$ parasites $/ \mathrm{ml}$ ) were grown in 24-well culture microplates at $25^{\circ} \mathrm{C}$ in Warren's medium supplemented with $10 \% \mathrm{FBS}$, and axenic amastigote forms $\left(1 \times 10^{6}\right.$ parasites $\left./ \mathrm{ml}\right)$ were grown in 12-well culture microplates at $32^{\circ} \mathrm{C}$ in Schneider's medium supplemented with $20 \%$ FBS. The parasites were incubated in the presence or absence of 2.7, 13.9, 27.7, 139, and $277 \mu \mathrm{M}$ BZTS and incubated for 72 h. Dimethyl sulfoxide (DMSO) was used to solubilize the stock solution of the compound. The final DMSO concentration did not exceed $1 \%$, which has no deleterious effects on the parasites. Antileishmania activity was determined by directly counting free-living parasites in a Neubauer chamber, and the concentration that inhibited growth by $50 \%\left(\mathrm{IC}_{50}\right)$ was determined graphically by plotting the concentration $v s$. percentage growth inhibition.

\section{Activity against intracellular amastigotes}

Peritoneal macrophages were collected from BALB/c mice by washing with cold phosphate-buffered saline (PBS) 
supplemented with 3\% FBS (The protocol was approved by the Ethical Committee of the State University of Maringa. Approval no. 074/2011). Sterile glass coverslips were placed in the wells of a 24-well microplate, and $5 \times 10^{5}$ cells $/ \mathrm{ml}$ were added to each well in RPMI 1640 medium supplemented with $10 \%$ FBS. The microplate was incubated for $2 \mathrm{~h}$ at $37^{\circ} \mathrm{C}$ in a $5 \% \mathrm{CO}_{2}$-air mixture to adhere macrophages. The macrophage monolayer was infected with promastigote forms at a 7:1 parasite: macrophage ratio. After $4 \mathrm{~h}$ of interaction at $34^{\circ} \mathrm{C}$ in a $5 \%$ $\mathrm{CO}_{2}$-air mixture, the microplate was washed with RPMI 1640 medium to remove the non-interiorized parasites. Afterward, the infected macrophages were treated with BZTS at concentrations of 2.7, 5.5, 13.9, and 27.7 $\mu \mathrm{M}$ and incubated for $48 \mathrm{~h}$. The percentage of infected macrophages was evaluated after Giemsa staining by microscopically counting the number of amastigotes per macrophage.

\section{In vitro cytotoxicity assay}

The J774A1 macrophage cell monolayer was suspended to yield $5 \times 10^{5}$ cells $/ \mathrm{ml}$ in RPMI 1640 medium supplemented with $10 \%$ FBS and added to each well in 96-well microtiter plates. The plates were incubated in a $5 \%$ $\mathrm{CO}_{2}$-air mixture at $37^{\circ} \mathrm{C}$ to obtain confluent cell growth. The macrophage monolayer was treated with different concentrations of BZTS $(2.7,13.9,27.7,139$, and $277 \mu \mathrm{M})$ for $48 \mathrm{~h}$. After treatment, the medium was removed, and the macrophage monolayer was washed with PBS, and $50 \mu \mathrm{L}$ of MTT (3-[4,5-dimethylthiazol-2-yl]2,5-diphenyltetrazolium bromide formazan; $2 \mathrm{mg} / \mathrm{mL}$ ) was added. The microplate was then incubated for $4 \mathrm{~h}$ in a $5 \% \mathrm{CO}_{2}$-air mixture at $37^{\circ} \mathrm{C}$. After the incubation period, $150 \mu \mathrm{l}$ DMSO was added, and the microplate was homogenized. Absorbance was read in a microplate reader (BIO-TEK Power Wave XS) at $570 \mathrm{~nm}$. The percentage of viable macrophages was calculated compared with controls (i.e., macrophages cultured in medium without drug). The $50 \%$ cytotoxic concentration $\left(\mathrm{CC}_{50}\right)$ was determined by logarithm regression analysis of the data.

\section{Electron microscopy Scanning electron microscopy}

For the morphological analysis, promastigotes that were treated for $72 \mathrm{~h}$ at $25^{\circ} \mathrm{C}$ with concentrations that corresponded to the $\mathrm{IC}_{50}$ and $\mathrm{IC}_{90}$ for BZTS were fixed in $2.5 \%$ glutaraldehyde in $0.1 \mathrm{M}$ sodium cacodylate buffer for 1-3 h. Subsequently, parasites were adhered on polyL-lysine-coated coverslips and dehydrated in an ascending series of ethanol. The samples were critical-point-dried in $\mathrm{CO}_{2}$, coated with gold, and observed in a Shimadzu SS550 scanning electron microscope.

\section{Transmission electron microscopy}

Ultrastructural analysis was performed with promastigote and axenic amastigote forms that were treated for $72 \mathrm{~h}$ at $25^{\circ} \mathrm{C}$ and $32^{\circ} \mathrm{C}$ with concentrations that corresponded to the $\mathrm{IC}_{50}$ and $\mathrm{IC}_{90}$ for BZTS, respectively. After washing with PBS, the parasites were fixed in $2.5 \%$ glutaraldehyde in $0.1 \mathrm{M}$ sodium cacodylate buffer at $4{ }^{\circ} \mathrm{C}$ and post-fixed in a solution that contained $1 \%$ osmium tetroxide, $0.8 \%$ potassium ferrocyanide, and $5 \mathrm{mM}$ calcium chloride. The parasites were dehydrated in an acetone series and embedded in Epon resin for $72 \mathrm{~h}$ at $60^{\circ} \mathrm{C}$. Ultrathin sections were stained with 5\% uranyl acetate and lead citrate and examined in a JEOL JEM 1400 transmission electron microscope.

\section{Flow cytometry}

\section{Evaluation of cell membrane integrity}

Promastigotes were exposed to 55, 139, 277, and $555 \mu \mathrm{M}$ BZTS for $24 \mathrm{~h}$ at $25^{\circ} \mathrm{C}$ and then harvested and washed with PBS. The cells were incubated with $50 \mu \mathrm{l}$ of $2 \mathrm{mg} / \mathrm{ml}$ propidium iodide (PI) for $5 \mathrm{~min}$ according to the manufacturer's instructions. Immediately thereafter, the cells were analyzed using a BD FACSCalibur flow cytometer equipped with CellQuest Pro software. A total of 10,000 events were acquired in the region that corresponded to the parasites. Alterations in PI fluorescence were determined compared with untreated parasites. Digitonine $(40.0 \mu \mathrm{M})$ was used as a positive control.

\section{Determination of mitochondrial transmembrane potential $\left(\Delta \psi_{m}\right)$}

Promastigotes were exposed to 55, 139, 277, and $555 \mu \mathrm{M}$ BZTS for $24 \mathrm{~h}$ at $25^{\circ} \mathrm{C}$. The cells were then incubated with $1 \mu \mathrm{l}(5 \mathrm{mg} / \mathrm{ml}$ in ethanol) of rhodamine 123 (Rh 123; Sigma-Aldrich, St. Louis, MO, USA) for $15 \mathrm{~min}$, resuspended in $0.5 \mathrm{ml} \mathrm{PBS}$, and incubated for an additional $30 \mathrm{~min}$. The assay was conducted according to the manufacturer's instructions. The parasites were analyzed using a BD FACSCalibur flow cytometer and CellQuest Pro software. A total of 10,000 events were acquired in the region that corresponded to the parasites. Carbonyl cyanide 3-chlorophenylhydrazone (CCCP; 100.0 $\mu \mathrm{M}$ ) was used as a positive control. Alterations in $\mathrm{Rh} 123$ fluorescence were quantified using an index of variation (IV) obtained from the equation $(M t-M c)$ / $M c$, in which $\mathrm{Mt}$ is the median fluorescence for the BZTStreated parasites, and $\mathrm{Mc}$ is the median fluorescence for the untreated parasites. Negative IV values correspond to depolarization of the mitochondrial membrane.

\section{Detection of phosphatidylserine exposure by annexin-V-FITC labeling}

Promastigotes were treated with BZTS (55, 139, 277 and $555 \mu \mathrm{M})$ for $24 \mathrm{~h}$ at $25^{\circ} \mathrm{C}$ and then harvested and washed 
with PBS. The cells were then resuspended in $500 \mu \mathrm{l}$ of binding buffer $(140 \mathrm{mM} \mathrm{NaCl}, 5 \mathrm{mM} \mathrm{CaCl}$, and $10 \mathrm{mM}$ HEPES-Na, $\mathrm{pH} 4.7$ ), followed by the addition of $5 \mu \mathrm{l}$ of FITC-conjugated annexin V. The reaction was incubated for $5 \mathrm{~min}$ at room temperature. Afterward, $400 \mu \mathrm{l}$ of binding buffer and $50 \mu \mathrm{l}$ PI were added. Fluorescence was measured using a BD FACSCalibur flow cytometer and CellQuest Pro software. A total of 10,000 events were acquired in the region that corresponded to the parasites as described above. CCCP $(100.0 \mu \mathrm{M})$ was included as a positive control, and untreated parasites served as the negative control. The parasites were considered necrotic when they were PI-positive and apoptotic when stained with annexin-V (PI-positive or -negative).

\section{Determination of cell volume of parasites}

Promastigotes were treated with BZTS $(55,139,277$, and $555 \mu \mathrm{M})$ for $24 \mathrm{~h}$ at $25^{\circ} \mathrm{C}$ and then harvested and washed with PBS. The parasites were then analyzed using a BD FACSCalibur flow cytometer and CellQuest Pro software. Density plots of forward (FSC) vs. side (SSC) scatter represent the acquisition of 10,000 events.

\section{Fluorimetric detection of mitochondrial superoxide anion radical $\left(\mathrm{O}_{2}^{-}\right)$}

Promastigotes were harvested and washed with KrebsHenseleit $(\mathrm{KH})$ solution buffer, $\mathrm{pH} 7.3$, that contained $15 \mathrm{mM} \mathrm{NaHCO}_{3}, 5 \mathrm{mM} \mathrm{KCl}, 120 \mathrm{mM} \mathrm{NaCl}$, and 0.7 and $1.5 \mathrm{mM} \mathrm{NaH} \mathrm{PO}_{4}$. The cells were loaded with $2.0 \mathrm{ml}$ of $5 \mu \mathrm{M}$ MitoSOX reagent (3,8-phenanthridinediamine-5-[6-triphenylphosphoniumhexyl]-5,6-dihydro6-phenyl). The parasites were incubated for $10 \mathrm{~min}$ at $37^{\circ} \mathrm{C}$ and protected from light. After incubation with MitoSOX reagent, the parasites were washed three times with $\mathrm{KH}$ buffer and treated with $55,139,277$, and $555 \mu \mathrm{M}$ BZTS. Antimycin A $(10 \mu \mathrm{M})$ was used as a positive control. MitoSOX detection was performed using black 96-well plates for $3 \mathrm{~h}$. Fluorescence was measured at excitation and emission wavelengths of 510 and $580 \mathrm{~nm}$, respectively, in a VICTOR X3 spectrofluorometer (Perkin Elmer). The results are expressed as arbitrary units of MitoSOX.

\section{Detection of cytoplasmic lipid bodies by nile red staining} Promastigote forms of $L$. amazonensis were treated with concentrations that corresponded to the $\mathrm{IC}_{50}$ and $\mathrm{IC}_{90}$ for BZTS as described previously in an antiproliferative assay. The treated parasites were then harvested, washed twice in PBS, and directly stained with $10 \mu \mathrm{g} / \mathrm{ml} \mathrm{Nile}$ Red (Sigma-Aldrich, St. Louis, MO, USA) for $30 \mathrm{~min}$ at room temperature. The cytoplasmic lipid bodies in the parasites were detected with an epifluorescence microscope (Olympus BX51) equipped with a WG filter. The parasites were photographed using an Olympus UC30 camera.

\section{Statistical analysis}

In the cellular experiments, the $50 \%$ growth inhibition value $\left(\mathrm{IC}_{50}\right)$ was determined from the linear concentrationresponse curves, and the results are expressed as the mean and standard deviation of at least three independent experiments. Nonparametric data were analyzed using one-way analysis of variance (ANOVA), and significant intergroup differences were analyzed using Tukey's test. All of the statistical analyses were performed at the $p<0.05$ level of significance.

\section{Additional files}

Additional file 1: Graphical 1. Inhibition percentage of promastigote and axenic amastigote forms of Leishmania amazonensis treated with BZTS for $72 \mathrm{~h}$. The data are expressed as the means from three independent tests.

Additional file 2: Graphical 2. Inhibition percentage of intracellular amastigote forms of Leishmania amazonensis treated with BZTS for $48 \mathrm{~h}$. The data are expressed as the means from three independent tests.

Additional file 3: Graphical 3. Inhibition percentage of J774A1 macrophages after treatment with BZTS for $48 \mathrm{~h}$. The data are expressed as the means from three independent tests.

\section{Competing interests}

The authors declare that they have no competing interests.

\section{Authors' contributions}

EAB conceived and designed the study, carried out all the experimental studies and drafted the manuscript. DBS participated in the experimental studies and drafted the manuscript. HF and CCS synthetisized the compound of the study. TUN, BPDF and RB participated in the design of the study. CVN conceived of the study and participated in its design and coordination and helped to draft the manuscript. All authors read and approved the final manuscript.

\section{Acknowledgements}

This study was supported through grants Coordenação de Aperfeiçoamento de Pessoal de Nível Superior (Capes), Financiadora de Estudos e Projetos (FINEP), Programa de Núcleos de Excelência (PRONEX/Fundação Araucária), Complexo de Centrais de Apoio a Pesquisa (COMCAP), and Programa de Pós-graduação em Ciências Farmacêuticas da Universidade Estadual de Maringá. EAB has a Doctorate fellowship from Coordenação de

Aperfeiçoamento de Pessoal de Nível Superior (Capes). RB acknowledges the support from Institut Carnot PolyNat, Labex Arcane and the ICMG Chemistry Nanobio Platform, Grenoble.

\section{Author details}

${ }^{1}$ Programa de Pós-graduação em Ciências Farmacêuticas, Universidade Estadual de Maringá, Avenida Colombo, Jd. Universitário, Maringá, PR 5790, Brazil. Departamento de Química, Universidade Estadual de Maringá, Maringá, PR, Brazil. ' Université Grenoble Alpes, CERMAV-CNRS UPR 5301, Grenoble F-38000, France.

Received: 18 June 2014 Accepted: 20 August 2014

Published online: 26 September 2014

\section{References}

1. World Health Organization: Parasitic Disease. In World Health Organization; Available via internet: http://www.who.int/leishmaniasis/en/index.html. [Online early access: May/13/2014]. 
2. Chappuis F, Alirol E, Worku DT, Mueller Y: High mortality among older patients treated with pentavalent antimonials for visceral Leishmaniasis in East Africa and rationale for switch to Liposomal Amphotericin B. Antimicrob Agents Chemother 2011, 55(1):455-456.

3. Desjeux P: Leishmaniasis: current situation and new perspectives. Comp Immunol Microbiol Infect Dis 2004, 27(5):305-318.

4. Cunha-Júnior EF, Pacienza-Lima W, Ribeiro GA, Netto CD, Canto-Cavalheiro MM, Silva AJM, Costa PR, Rossi-Bergmann B, Torres-Santos EC: Effectiveness of the local or oral delivery of the novel naphthopterocarpanquinone LQB-118 against cutaneous leishmaniasis. J Antimicrob Chemother 2011, 66(7):1555-1559.

5. Gingras BA, Hornal RW, Hayley CH: The preparation of some thiosemicarbazones and their copper complexes: Part I. Can J Chem 1960, 38(5):712-719.

6. Beraldo H, Gambino D: The wide pharmacological versatility of semicarbazones, thiosemicarbazones and their metal complexes. Min Rev Med Chem 2004, 4(1):31-39.

7. Pelosi G: Thiosemicarbazone metal complexes: from structure to activity. The Open Crystallography Journal 2010, 3(1):16-28.

8. Knox JJ, Hotte SJ, Kollmannsberger C, Winquist E, Fisher B, Eisenhauer EA: Phase II study of Triapine ${ }^{\circledast}$ in patients with metastatic renal cell carcinoma: a trial of the National Cancer Institute of Canada Clinical Trials Group (NCIC IND.161). Invest New Drugs 2007, 25(5):471-477.

9. U.S. National Institutes of Health: Available via internet: http://clinicaltrials. gov/show/NCT01835171. [Online early access: March/13/2014]

10. Hernández W, Paz J, Carrasco F, Vaisberg A, Spodine E, Manzur J, Lothar H, Joachim S, Steffen B, Lothar B: Synthesis and characterization of new palladium(ii) thiosemicarbazone complexes and their cytotoxic activity against various human tumor cell lines. Bioinorg Chem Appl 2013, 12. doi:10.1155/2013/524701

11. Li MX, Chen CL, Zhang D, Niu JY, Ji BS: Mn(II), Co (II) and Zn(II) complexes with heterocyclic substituted thiosemicarbazones: synthesis, characterization, X-ray crystal structures and antitumor comparison. Eur J Med Chem 2010, 45(7):3169-3177.

12. Qin Y, Xing R, Liu S, Li K, Meng X, Li R, Cui J, Li B, Li P: Novel thiosemicarbazone chitosan derivatives: preparation, characterization, and antifungal activity. Carbohydr Polym 2012, 87(4):2664-2670.

13. Britta EA, Silva APB, Ueda-Nakamura T, Dias-Filho BP, Silva CC, Sernaglia RL, Nakamura CV: Benzaldehyde thiosemicarbazone derived from limonene complexed with copper induced mitochondrial dysfunction in Leishmania amazonensis. Plos One 2012, 7(8):e41440. doi:10.1371/journal.pone.0041440.

14. Castro EF, Fabian LE, Caputto ME, Gagey D, Finkielsztein LM, Moltrasio GY, Moglioni AG, Campos RH, Cavallaro LV: Inhibition of bovine viral diarrhea virus RNA synthesis by thiosemicarbazone derived from 5,6-dimethoxy1-indanone. J Virol 2011, 85(11):5436-5445.

15. Chen LH, Hu YH, Song W, Song KK, Liu X, Jia YL, Zhuang JX, Chen QX: Synthesis and antityrosinase mechanism of benzaldehyde thiosemicarbazones: novel tyrosinase inhibitors. J Agric Food Chem 2012, 60(6):1542-1547.

16. Goto H, Lindoso JAL: Cutaneous and mucocutaneous Leishmaniasis. Infect Dis Clin 2012, 26(2):293-307.

17. Arruda DC, Miguel DC, Yokoyama-Yasunaka JKU, Katzin AM, Uliana SRB: Inhibitory activity of limonene against Leishmania parasites in vitro and in vivo. Biomed Pharmacother 2009, 63(9):643-649.

18. Santin MR, Santos AO, Nakamura CV, Dias-Filho BP, Ferreira ICP, UedaNakamura T: In vitro activity of the essencial oil of Cymbopogon citratus and its major component (citral) on Leishmania amazonensis. Parasitol Res 2009, 105(6):1489-1496.

19. Valdez RH, Tonin LTD, Ueda-Nakamura T, Dias-Filho BP, Morgado-Díaz JA, Sarragiotto MH, Nakamura CV: Biological activity of 1,2,3,4-tetrahydro- $\beta$ carboline-3-carboxamides against Trypanosoma cruzi. Acta Trop 2009, 110(1):7-14

20. Aponte JC, Castilho D, Estevez Y, Gonzalez G, Arevalo J, Hammond GB, Sauvain M: In vitro and in vivo anti-Leishmania activity polysubstituted synthetic chalcones. Bioorg Med Chem Lett 2010, 20(1):100-103.

21. Graebin CS, De Madeira MF, Yokoyama-Yasunaka JKU, Miguel DC, Uliana SRB, Benitez D, Cerecetto H, González M, Rosa RG, Eifler-Lima VL: Synthesis and in vitro activity of limonene derivatives against Leishmania and Trypanosoma. Eur J Med Chem 2010, 45(4):1524-1528.

22. Inácio JDF, Canto-Cavalheiro MM, Menna-Barreto RFS, Almeida-Amaral EE: Mitochondrial damage contribute to epigallocatechin-3-gallate induced death in Leishmania amazonensis. Exp Parasitol 2012, 132(2):151-155.
23. Monzote L, García M, Pastor J, Gil L, Scull R, Maes L, Cos P, Gille L: Essencial oil from Chenopodium ambrosioides and main components: activity against Leishmania, their mitochondria and other microorganisms. Exp Parasitol 2014, 136:20-26.

24. Takahashi H, Britta EA, Longhini R, Ueda-Nakamura T, de Mello JC P, Nakamura CV: Antileishmanial activity of 5-methyl-2,2':5,2"-terthiophene isolated from Porophyllum ruderale is related to mitochondrial dysfunction in Leishmania amazonensis. Planta Med 2013, 79(5):330-333.

25. Volpato H, Desoti VC, Cogo J, Panice MR, Sarragioto MH, Silva SO, UedaNakamura T, Nakamura CV: The effects of $\mathrm{N}$-butyl-1-(4-dimethylamino) phenyl-1,2,3,4-tetrahydro- $\beta$-carboline-3-carboxamide against Leishmania amazonensis are mediated by mitochondrial dysfunction. Evid Based Complement Alternat Med 2013, 2013:874367. doi:10.1155/2013/874367.

26. Lazarin-Bidóia D, Desoti VC, Ueda-Nakamura T, Dias-Filho BP, Nakamura CV, Silva SO: Further evidence of the trypanocidal action of eupomatenoid-5: confirmation of involvement of reactive oxygen species and mitochondria owing to a reduction in trypanothione reductase activity. Free Radic Biol Med 2013, 60:17-28.

27. Garcia FP, Lazarin-Bidóia D, Ueda-Nakamura T, Silva SO, Nakamura CV: Eupomatenoid-5 isolated from leaves of Piper regnellii induces apoptosis in Leishmania amazonensis. Evid Based Complement Alternat Med 2013, 2013:940531. doi:10.1155/2013/940531.

28. Luque-Ortega JR, Reuther P, Rivas L, Dardonville C: New Benzophenonederived Bisphosphonium Salts as Leishmanicidal leads targeting mitochondria through inhibition of respiratory complex II. J Med Chem 2010, 53(4):1788-1798

29. Desoti VC, Lazarin-Bidóia D, Sudati DB, Pereira RC, Alonso A, Ueda-Nakamura T, Dias-Filho BP, Nakamura CV, Silva SO: Trypanocidal action of (-)-Elatol involves an oxidative stress triggered by mitochondria dysfunction. Mar Drugs 2012, 10(8):1631-1646.

30. Medina JM, Rodrigues JCF, De Souza W, Atella GC, Barrabim H: Tomatidine promotes the inhibition of 24-alkylated sterol biosynthesis and mitochondrial dysfunction in Leishmania amazonensis promastigotes. Parasitology 2012, 139(10):1253-1265.

31. Serrano-Martín X, García-Marchan Y, Fernandez A, Rodriguez N, Rojas H, Visbal G, Benaim G: Amiodarone destabilizes intracellular $\mathrm{Ca}^{2+}$ homeostasis and biosynthesis of sterols in Leishmania mexicana. Antimicrob Agents Chemother 2009, 53(4):1403-1410.

32. Macedo-Silva ST, Silva TLAO, Urbina JÁ, De Souza W, Rodrigues JCF: Antiproliferative, ultrastructural, and physiologycal effects of amiodarone on promastigote and amastigote forms of Leishmania amazonensis. Mol Biol Int 2011, 876021-12. doi:10.4061/2011/876021.

33. Shioji Tiuman T, Ueda-Nakamura T, Alonso A, Nakamura CV: Cell death in amastigote forms of Leishmania amazonensis induced by partenolide. BMC Microbiol 2014, 14(1):152.

34. Godinho JLP, Georgikopoulou K, Calogeropoulou T, De Souza W, Rodrigues $J C$ : A novel alkyl phosphocholine-dinitroaniline hybrid molecule exhibits biological activity in vitro against Leishmania amazonensis. Exp Parasitol 2013, 135(1):153-165.

35. Shivahare $R$, Korthikunta V, Chandasana $H$, Suthar MA, Agnihotri $P$, Vishwakarma P, Chaitanya TK, Kancharla P, Khaliq T, Gupta S, Bhatta RS, Pratap JV, Saxena JK, Gupta S, Tadigoppula N: Structure - activity relationships, and biological studies of chromenochalcones as potential antileishmanial agents. J Med Chem 2014, 57(8):3342-3357.

36. Rodrigues JCF, Attias M, Rodriguez C, Urbina JA, De Souza W: Ultrastructural and biochemical alterations induced by 22,26 -Azasterol, a $\Delta^{24(25)}$-Sterol methyltransferase inhibitor, on promastigote and amastigote forms of Leishmania amazonensis. Antimicrob Agents Chemother 2002, 46(2):487-499.

37. Yamaguchi MU, Da Silva APB, Ueda-Nakamura T, Dias-Filho BP, Da Silva CC, Nakamura CV: Effects of a Thiosemicarbazone Camphene derivate on Trichophyton mentagrophytes. Molecules 2009, 15(5):1796-1807.

doi:10.1186/s12866-014-0236-0

Cite this article as: Britta et al.: Cell death and ultrastructural alterations in Leishmania amazonensis caused by new compound 4-Nitrobenzaldehyde thiosemicarbazone derived from S-limonene. BMC Microbiology 2014 14:236. 